\title{
A cross-sectional study investigating the impact of cultural heritage on cardiovascular risk factors in Greek-Cypriot adults living the UK
}

\author{
C. Andronikou, L. O’Connor and T.J Butler \\ Department of Health Professions, Manchester Metropolitan University, Manchester, M15 6BG
}

Food intake is determined by factors such a taste, appetite, income, affordability, cooking skills and education, in addition to family and culture ${ }^{(1)}$. The importance of culture and acculturation may explain why certain populations display greater frequency of lifestyle risk factors for cardiovascular disease (CVD) disease such as weight gain and higher consumption of high-fat/high-sugar foods ${ }^{(2,3)}$. However, the process of acculturation assumes that the diet prior to migration is of better quality and may be dependent on the country of origin. The aim of this study was to determine whether second generation Greek-Cypriot (GC) adults living in the UK display differences in lifestyle risk factors for CVD in comparison to a UK population.

Participants were sampled from networks in Manchester and Liverpool and matched for age. Those meeting the criteria of having at least one GC parent were included in the study. Individuals with British (BR) parents were used as a comparison group. Diet was assessed using the EPIC Norfolk food frequency questionnaire (FFQ), and analysed with particular focus on cardioprotective components such as fruits and vegetables, nuts and seeds, and dietary fats. Weight and height were measured, and BMI calculated. Smoking status was also determined. All procedures were approved by the research ethics committee at Manchester Metropolitan University.

\begin{tabular}{|c|c|c|c|c|c|c|c|}
\hline \multirow[b]{2}{*}{ Group } & \multicolumn{2}{|c|}{ Age (years) } & \multicolumn{2}{|c|}{ Weight (kg) } & \multicolumn{2}{|c|}{ BMI $\left(\mathrm{kg} / \mathrm{m}^{2}\right)$} & \multirow{2}{*}{$\begin{array}{l}\text { Current smoker } \\
\text { Frequency }(\%)\end{array}$} \\
\hline & Mean & $\mathrm{SD}$ & Mean & SD & Mean & $\mathrm{SD}$ & \\
\hline Total (n 52) & $47 \cdot 8$ & $14 \cdot 2$ & $77 \cdot 8$ & $16 \cdot 3$ & $27 \cdot 0$ & $5 \cdot 0$ & $9(17.9)$ \\
\hline $\mathrm{BR}(n$ 26) & $48 \cdot 8$ & $13 \cdot 4$ & $80 \cdot 1$ & $16 \cdot 8$ & $27 \cdot 9$ & $4 \cdot 6$ & $5(9 \cdot 6)$ \\
\hline GC ( $\left.\begin{array}{ll}n & 26\end{array}\right)$ & $46 \cdot 7$ & $15 \cdot 2$ & $75 \cdot 3$ & $15 \cdot 7$ & $26 \cdot 1$ & $5 \cdot 2$ & $4(7 \cdot 7)$ \\
\hline
\end{tabular}

Of the 58 screened individuals, 52 met the inclusion criteria and were included in the study and analyses. No significant differences were found for weight, BMI and smoking status between BR and GC groups. Analysis of the FFQ showed no significant difference between BR and GC groups for energy intake (1723 $\pm 607 \mathrm{kcal}$ vs. $1738 \pm 674 \mathrm{kcal}, P=0.634$, respectively), protein $(78.4 \pm 22.7 \mathrm{~g} / \mathrm{d}$ vs. $95.4 \pm 44.4 \mathrm{~g} / \mathrm{d}, P=0.188$, respectively $)$ total carbohydrate $(204 \pm 101 \mathrm{~g} / \mathrm{d}$ vs. $183 . \pm 61 \mathrm{~g} / \mathrm{d}, P=0.647$, respectively $)$ and total fat $(68.1 \pm 24.0 \mathrm{~g} / \mathrm{d}$ vs. $73.4 \pm 32.5 \mathrm{~g} / \mathrm{d}, P=0.756$, respectively). Consumption of MUFA and PUFA did not differ between BR and GC groups $\left(P=0.388 ; P=0.206\right.$, respectively). Food group analysis showed the median $\left(25^{\text {th }}\right.$, $75^{\text {th }}$ percentile $)$ consumption of nuts and seeds was significantly $(P=0.001)$ greater in the GC group $(12.9 \mathrm{~g} / \mathrm{d}[2.6,23.1])$ vs. the BR group [0.7 g/d $(0 \cdot 0,3.8)]$. Intake of non-alcoholic beverages was significantly $(P=0.049)$ higher in the BR group ( $854 \pm 497 \mathrm{~g} / \mathrm{d})$ vs. the GC group $(580 \pm$ $480 \mathrm{~g} / \mathrm{d})$. No significant differences were found for other food group components of the FFQ.

These findings suggest that a second generation GC population have similar lifestyle risk factors for CVD in comparison to a BR group of similar age. This suggest that second generation GC are largely acculturated to the UK, although cultural remnants such as higher nut consumption remain. This may offer some protection against CVD to those of GC descent living in the UK.

1. Leng G, Adan RA, Belot M et al. (2016) Proc Nutr Soc 1-12.

2. Wu B and Smith C (2016) Appetite 103 324-335.

3. Hartwell HJ, Edwards JS, Brown L (2011) Brit Food J 113 1393-1405. 